\title{
Bacterial profile, antibiotic susceptibility pattern and associated risk factors of urinary tract infection among clinically suspected children attending at Felege- Hiwot comprehensive and specialized
} hospital, Northwest Ethiopia. A prospective study

Adugna Fenta ${ }^{1}$, Mulat Dagnew ${ }^{2}$, Setegn Eshetie ${ }^{2}$ and Teshome Belachew ${ }^{2 *}$ (I)

\begin{abstract}
Background: Urinary tract infection is one of the most common bacterial infections in children. Understanding the characteristics of uropathogens and their antimicrobial susceptibility pattern in a particular setting can provide evidence for the appropriate management of cases. This study aimed to assess the bacterial profile of urinary tract infection, their antimicrobial susceptibility pattern and associated factors among clinically suspected children attending at Felege-Hiwot Comprehensive Specialized Hospital, Northwest Ethiopia.

Methods: A hospital-based cross-sectional study was conducted from February-April, 2019. A systematic sampling technique was employed. A mid-stream urine sample was inoculated on cystine lactose electrolyte deficient media and incubated for 24-48 h. Sub-culturing was done on Mac-Conkey and blood agar. Antimicrobial susceptibility test was done on Muller-Hinton agar. A binary logistic regression model was used to see the association between dependent and independent factors. A $p$-value $<0.05$ at 95\% Cl was considered as statistically significant.

(Continued on next page)
\end{abstract}

\footnotetext{
* Correspondence: tesh0926@gmail.com

${ }^{2}$ College of Medicine and Health Sciences, School of Biomedical and Laboratory Sciences, Department of Medical Microbiology, University of Gondar, Gondar, Ethiopia

Full list of author information is available at the end of the article
}

(c) The Author(s). 2020 Open Access This article is licensed under a Creative Commons Attribution 4.0 International License, which permits use, sharing, adaptation, distribution and reproduction in any medium or format, as long as you give appropriate credit to the original author(s) and the source, provide a link to the Creative Commons licence, and indicate if changes were made. The images or other third party material in this article are included in the article's Creative Commons licence, unless indicated otherwise in a credit line to the material. If material is not included in the article's Creative Commons licence and your intended use is not permitted by statutory regulation or exceeds the permitted use, you will need to obtain permission directly from the copyright holder. To view a copy of this licence, visit http://creativecommons.org/licenses/by/4.0/ The Creative Commons Public Domain Dedication waiver (http://creativecommons.org/publicdomain/zero/1.0/) applies to the data made available in this article, unless otherwise stated in a credit line to the data. 


\begin{abstract}
(Continued from previous page)
Results: The overall prevalence of urinary tract infection was 16.7\% (95\% Cl 12.4-21.1). Both Gram-negative and Gram-positive bacterial isolates were recovered with a rate of $44 / 50$ (88\%) and 6/50 (12\%) respectively. Among Gram-negative isolates, E. coli 28/44(63.6\%) was predominant while S. saprophyticus 2/6(33.3\%) was prevalent among Gram-positive bacterial isolates. Overall, a high level of resistance to ampicillin, augmentin, and tetracycline was shown by Gram-negative bacteria with a rate of $44 / 44(100 \%), 39 / 44(88.6 \%)$, and36/44 (81.8\%) respectively. About 33/50(66\%) of overall multidrug resistance was observed ( $95 \% \mathrm{Cl} 52-78$ ). About six Gram-negative bacterial isolates were extended spectrum beta-lactamase (ESBL) producers. Having a history of urinary tract infection (P0.003, AOR 1.86-22.15) and male uncircumcision ( $p-0.00$, AOR 5.5-65.35) were the independent variables that associate for urinary tract infections.
\end{abstract}

Conclusion: In the present study, the prevalence of urinary tract infection among children was high and considerably a high proportion of multidrug resistance was observed. This result will have a significant impact on the selection of appropriate antimicrobial agents for the treatment of urinary tract infection.

Keywords: Bacterial isolates, Antimicrobial susceptibility, Children, Associated factors

\section{Background}

Urinary tract infection (UTI) is a serious bacterial infection causing illness in infants and children. It is one of the most common bacterial infections faced by clinicians working in the developing world [1]. The term UTI is applied to a variety of clinical conditions ranging from the asymptomatic presence of bacteria in the urine to severe infection of the kidney with the development of sepsis. If poorly treated or undiagnosed, it is an important cause of long-term morbidities like; hypertension, failure to thrive, and finally go to end-stage renal dysfunction [2, 3]. Developing kidneys of infants and young children are more susceptible to damage from pyelonephritis [4].

The epidemiology of UTI during childhood varies by age, gender, circumcision status, and other factors. Boys are more susceptible during the first year of life, mostly in the first 3 months, among boys, uncircumcised infants have an eightfold higher risk; due to phimosis, limited retraction of the foreskin is significantly associated with an increase in UTIs in male infants [5], afterward, the incidence is mainly higher in girls, due to differences in anatomy [6]. Common symptoms of UTIs include burning sensation during urination, loss of bladder control, increased frequency of urination especially in small amounts, low back pain, cloudy, and bloody or foulsmelling urine [7]. About $5 \%$ of girls and $2 \%$ of boys experience at least one incident of UTI up to the age of 7 years $[8,9]$.

Urinary tract infection is among the most prevailing infectious diseases with a considerable financial burden on society. It affects approximately 150 million people worldwide per year. Populations that have a major risk of acquiring a UTI are newborns, preschool children, sexually active women, and older individuals of both sexes [10]. Studies from developing countries showed that around $10 \%$ of children with febrile illnesses have a
UTI and it extends to $8-35 \%$ if the patient is malnourished children $[3,11]$.

It is estimated that globally $26 \%$ of deaths are due to infectious diseases such as UTIs of which $98 \%$ occur in low-income countries [7]. The prevalence of UTI in pediatrics of Asian countries was high. In Nepal, two studies were studied at different times from different areas and showed that 15.88 and $57 \%[12,13]$ of prevalence was documented. Another study in India also showed a $48 \%$ prevalence [14].

In South African children, a hospital-based study on prevalence, spectrum, and impact of healthcareassociated infection showed that UTI takes an $11 \%$ share [15]. Similarly, the study of the prevalence of UTI in one Nigerian teaching hospital to determine the incidence of urinary tract infection among children and adolescents was $11.9 \%$ [16]. In Tanzania, Children who presented prolonged duration of fever (7 days or longer) were more likely to have UTI, 16.8\% [17]. Another study in Kenya on the contribution of urinary tract infection to the burden of febrile illnesses in young children reported about $11.9 \%$ share [11].

In Ethiopia, different studies done in different study groups. The findings at Hawassa referral hospital among pediatric patients showed that the prevalence of UTI was 27.5\% [8]. Significant level of UTI was also reported at Yekatit 12 hospital Addis Ababa, 15.9\% [18] and at Gondar University hospital, 26.45\% [19]. But, in the study area, only one study was done in 2013 by Yerega B et al., but authors couldn't identify and test too many associated factors of UTI among children. Besides, antimicrobial resistance is very dynamic so that periodic regular screening is essential. Therefore, our study will help physicians to update their knowledge on prevalence, antimicrobial susceptibility pattern and associated risk factors to make informed diagnostic and therapeutic decisions in treating children. 


\section{Methods}

\section{Study setting, design, population, and sampling} techniques

An institution-based cross-sectional study was done among UTI suspected children from February-April, 2019 at Felege-Hiwot Comprehensive Specialized Hospital, Bahir-Dar, Amhara regional state. Bahir-Dar is the capital of the Amhara regional state in Northwest Ethiopia. The Town is located $576 \mathrm{~km}$ from the capital city of the country, Addis Ababa. Based on the 2007 Census conducted by the Central Statistical Agency (Ethiopia), Bahir Dar town has a total population of 221, 990. The hospital is a tertiary care referral hospital with around 400 beds and 9 operating tables serving over 7 million people. The hospital provides obstetrics, pediatric, internal medicine, ophthalmology, gynecology, and orthopedic surgery services [20]. The sample size (299) was determined by using a single population proportion formula by considering the prevalence of $26.45 \%$ [19], with a $95 \%$ confidence interval, and a $5 \%$ margin of error. Study participants were recruited by convenient sampling technique. Children who were $\leq 15$ years and suspected of urinary tract infection were included in this study. However, children who took antibiotics 2 weeks before data collection and children who were critically ill were excluded. In this study, all patients visiting FelegeHiwot Comprehensive and Specialized Hospital for a certain clinical disease diagnosis were considered as a source population. Whereas, children who are visiting Mother and Child Health (MCH) clinic for UTI diagnosis during the study period were considered as a target population.

\section{Data collection methods}

The standard questionnaire was prepared from reviewed literature and pre-tested. It was prepared in English and translated to the local language (Amharic) then translated back into English to check the accuracy of the translation. The questionnaire design included sociodemographic characteristics and associated risk factors. Data collection was done after obtaining written informed consent from parents/guardians. Sociodemographic and data related to associate factors were collected with face to face interview.

\section{Urine sample collection}

Clean voided mid-stream urine (MSU) specimens were collected from UTI suspected children in sterile bottles by the patient's parent with the assistant of nurse and investigator and transported to the laboratory within $2 \mathrm{~h}$ of collection. Contamination was managed by giving proper instruction on how to collect the sample correctly. When the patient is unable to provide urine sample catheters were used [21].

\section{Culture and identification techniques}

Collected urine from each patient was inoculated onto cysteine-lactose-electrolyte deficient agar CLED/ (Oxoid, Basingstoke, Hampshire, England) plates using a calibrated inoculating loop with a capacity of $0.001 \mathrm{ml}$. The inoculated plates were incubated for $24-48 \mathrm{~h}$ at $37^{\circ} \mathrm{C}$ aerobically. If growth observed, Plates with a colony count of $\geq 10^{5} \mathrm{cfu} / \mathrm{ml}$ were considered significant bacteriuria [22]. Then sub-cultured to Mac-Conkey agar (Oxoid, Basingstoke, Hampshire, England) and 5\% sheep blood agar (Oxoid, Basingstoke, Hampshire, England) [22]. Bacterial isolates were characterized/identified by Gram stain and biochemical tests; i.e. for Gram-positive bacteria: catalase test, novobiocin disk test and coagulase test were done while for Gram-negatives: Triple sugar iron agar test, indole motility test, citrate agar test, lysine decarboxylase agar test, urea agar test and oxidase test were done.

\section{Antimicrobial susceptibility testing (AST)}

Antimicrobial susceptibility test was carried out using the Kirby-Bauer disc diffusion method as per the Clinical Laboratory Standards Institute (CLSI) guidelines on Muller Hinton agar [23]. The suspension of 3-5 colonies of freshly grown test organism was prepared equivalent to $0.5 \mathrm{McF}$ arland standards. The surface of the MullerHinton agar was then completely covered by rotating the swab with the suspension. The plates were allowed to dry for 3-5 min: then discs were evenly distributed on the inoculated plate using sterile forceps and incubated at $37^{\circ} \mathrm{C}$ for $18-24 \mathrm{~h}$. The diameter of the zone of inhibition around the disc was measured using a ruler. Results were interpreted as Sensitive, Intermediate, and Resistance based on CLSI 2018 guideline [23]. For statistical analysis purpose, "intermediate" sensitivity results of bacterial isolates was grouped to "resistant" sensitivity results. The following routinely used antimicrobials were tested: ampicillin [10 $\mu \mathrm{g}$ ], gentamycin [10 $\mu \mathrm{g}$ ], amox-clav [20/10 $\mu \mathrm{g}]$, cefoxitin [30 $\mu \mathrm{g}]$, cefotaxime [30 $\mu \mathrm{g}]$, ciprofloxacin [5 $\mu \mathrm{g}$ ]; meropenem [10 $\mu \mathrm{g}$ ], cotrimoxazole [trimethoprim, 1.25/sulfamethoxazole, $23.75 \mu \mathrm{g}$ ], ceftazidime $[30 \mu \mathrm{g}]$, chloramphenicol $[30 \mu \mathrm{g}]$, tetracycline [30 $\mu \mathrm{g}]$, nitrofurantoin [300 $\mu \mathrm{g}]$, and erythromycin [15 $\mu \mathrm{g}$ ] [23]. Multi-drug resistance was defined as resistance of an isolate to three or more antimicrobial classes tested [24].

\section{Extended Spectrum $\beta$-lactamase detection Screening to ESBL production test}

Based on CLSI-2018, bacterial isolates showing zone of inhibition diameters $\leq 22 \mathrm{~mm}$ to ceftazidime [30 $\mu \mathrm{g}$ ] or $\leq$ $27 \mathrm{~mm}$ to cefotaxime [30 $\mu \mathrm{g}$ ] were subjected to ESBL production test [23]. Phenotypic confirmation of ESBL production was done by using the double-disk diffusion 
method; cefotaxime [30 $\mu \mathrm{g}]$ and cefotaxime-clavulanic acid $[30 / 10 \mu \mathrm{g}]$ or ceftazidime [30 $\mu \mathrm{g}]$ and ceftazidimeclavulanic acid [30/10 $\mu \mathrm{g}]$. The bacterial suspension was prepared while taking 2-3 fresh colonies and adjusted to $0.5 \mathrm{McF}$ arland standard. Lawn culture was done on the Mueller-Hinton Agar (MHA) plate. The ceftazidime and ceftazidime-clavulanic acid discs were placed at $20 \mathrm{~mm}$ apart on the agar surface and incubated overnight at $37^{\circ} \mathrm{C}$. After overnight incubation $\mathrm{a} \geq 5 \mathrm{~mm}$ increase in zone diameter for either cefotaxime or ceftazidime tested in combination with clavulanic acid, were taken as indicative for ESBL production. E. coli ATCC 25922 was used as an ESBL-negative whereas $K$. pneumoniae ATCC 700603 was used as an ESBL-positive reference strain [23].

\section{Data processing and analysis}

Data entry and analysis were done by using SPSS version 20 software. The results were presented through texts, tables, and graphs. Descriptive statistics were used to summarize socio-demographic data, bacterial profile and susceptibility patterns of isolates. Bivariate and multivariate logistic regression analysis was carried out to identify potential factors of urinary tract infection of children. A $P$ value $<0.2$ was considered statistically significant for bivariate analysis. Adjusted odds ratio at $95 \%$ CI was used to measure the association between potential risk factors and UTI in children. A $p$-value $<0.05$ at 95\% CI was considered as statistically significant.

\section{Ethical consideration}

Ethical clearance was obtained from the University of Gondar Biomedical Laboratory Sciences, Ethical Review Committee. The reference number of the ethical letter was "Ref no SBMLS/2123/11". Written parental consent/ assent was obtained from parents or guardians of children after explaining the purpose and objective of the study. Study participants who were not willing to participate in the study would not be forced to participate. They were informed that all data and sample obtained from them were kept confidential by using codes instead of any personal identifiers and is meant only for the purpose of the study. Positive results were communicated to health care providers.

\section{Results}

\section{Socio-demographic characteristics}

A total of 299 urinary tract infections (UTI) suspected children were included in the present study. Of the total study subjects, 165 (55.2\%) were males. The age range of the participants was between day 1 and 15 years with a median age of 6 years. About 158(53\%) of study participants were in the age group of 6-15 years (Table 1).
Table 1 Socio-demographic characteristics of UTI suspected children attending at Felege- Hiwot Comprehensive Specialized Hospital (FHCSH), Northwest, Ethiopia, February-April, 2019

\begin{tabular}{lll}
\hline Socio-demographic characteristics & Frequency & Percentage \\
\hline Sex & 165 & 55.2 \\
Male & 134 & 44.8 \\
Female & & \\
Age (in years) & 36 & 12.0 \\
$\quad<1$ & 105 & 35.2 \\
$1-5$ & 158 & 52.8 \\
6-15 & & \\
Residence & 91 & 30.4 \\
Urban & 208 & 69.6 \\
$\quad$ Rural & & \\
Educational status of father & 83 & 27.8 \\
$\quad$ Unable to read and write & 91 & 30.4 \\
Primary & 64 & 21.4 \\
$\quad$ High school & 61 & 20.4 \\
College and above & & \\
Educational status of mother & 127 & 42.5 \\
$\quad$ Unable to read and write & 65 & 21.7 \\
Primary & 19.4 \\
High school & 58 & 16.4 \\
College and above & 49 & 100 \\
Total & 299 &
\end{tabular}

\section{Prevalence of bacterial isolates from UTI suspected children}

The overall prevalence of urinary tract infections among children was $16.7 \%$ (95\%CI: $12.4-21.1, N=50)$. Of the total culture-positive participants, the majority, 30/50 (60\%), were females (Table 1).

Both Gram-negative and Gram-positive bacterial species were recovered, 44/50 (88\%) and 6/50(12\%), respectively. Among Gram-negative bacterial species, $E$. coli were the most frequently isolated bacteria followed by Klebsiella species, Citrobacter species, 28/44 (63.6\%), 7/44(15.9\%), and 6/44(13.6\%), respectively (Table 2). S. saprophyticus and $S$. aureus were Gram-positive bacteria isolated with a rate of $3 / 6(50 \%)$ each (Table 3$)$.

\section{Antimicrobial susceptibility patterns of gram-negative bacterial isolates}

Among tested Gram-negative bacterial isolates, about 43(97.7\%) were susceptible to meropenem, followed by ciprofloxacin 34(77.3\%), cefoxitin 33(75\%), ceftazidime $30(68.2 \%)$, and chloramphenicol 33(75\%). However, $44(100 \%)$ resistance rate was observed to ampicillin followed by augmentin 39(88.6\%) and tetracycline $36(81.8 \%)$. Above $75 \%$ of $E$. coli isolates were susceptible 
Table 2 Drug resistance patterns of Gram-negative bacterial isolates from urine samples of children at the FHCSH, Northwest, Ethiopia, February-April, 2019

\begin{tabular}{|c|c|c|c|c|c|c|c|c|c|c|c|c|c|}
\hline Bacterial Iso. & Sen. & AMP & GEN & AMC & CTX & CTX & CIP & MER & COT & CAZ & $\mathrm{CHL}$ & TET & NIT \\
\hline \multirow[t]{3}{*}{ E. coli $(n=28)$} & $\mathrm{S}$ & - & $\begin{array}{l}13 \\
(46.4)\end{array}$ & $5(17.9)$ & $24(85.7)$ & $23(82.1)$ & $21(75)$ & $27(96.4)$ & $12(42.9)$ & $21(75)$ & $23(82.1)$ & $6(21.4)$ & $23(82.1)$ \\
\hline & I & - & $7(25)$ & $7(25)$ & $1(3.6)$ & $1(3.6)$ & $1(3.6)$ & - & $4(14.2)$ & $3(10.7)$ & $1(3.6)$ & $6(21.4)$ & $1(3.6)$ \\
\hline & $\mathrm{R}$ & $28(100$ & $8(28.6)$ & $16(57.1)$ & $3(10.7)$ & $4(14.3)$ & $6(21.4)$ & $1(3.6)$ & $12(42.9$ & $4(14.3)$ & $4(14.3)$ & $16(57.2)$ & $4(14.3)$ \\
\hline \multirow[t]{3}{*}{ K.pneumoniae $(n=5)$} & $S$ & - & $1(20)$ & - & $3(60)$ & $4(70)$ & $4(70)$ & $5(100)$ & $2(40)$ & $4(80)$ & $3(60)$ & $1(20)$ & $4(80)$ \\
\hline & I & - & $2(40)$ & - & $2(40)$ & - & - & - & - & - & - & - & $1(20)$ \\
\hline & $\mathrm{R}$ & $5(100)$ & $2(40)$ & $5(100)$ & - & $1(20)$ & $1(20)$ & - & $3(60)$ & $1(20)$ & $2(40)$ & $4(80)$ & - \\
\hline \multirow[t]{2}{*}{ K.ozaniae $(n=1)$} & S & & $1(100)$ & - & $1(100)$ & $1(100)$ & $1(100)$ & $1(100)$ & - & $1(100)$ & $1(100)$ & - & $1(100)$ \\
\hline & $\mathrm{R}$ & $1(100)$ & - & $1(100)$ & - & - & - & - & $1(100)$ & - & - & $1(100)$ & - \\
\hline \multirow{3}{*}{$\begin{array}{l}\text { K.rhinoscleromatis }(n= \\
\text { 1) }\end{array}$} & S & - & - & - & $1(100)$ & $1(100)$ & - & $1(100)$ & $1(100)$ & $1(100)$ & $1(100)$ & - & $1(100)$ \\
\hline & I & - & - & $1(100)$ & - & - & $1(100)$ & - & - & - & - & - & - \\
\hline & $\mathrm{R}$ & $1(100)$ & $1(100)$ & - & - & - & - & - & - & - & - & $1(100)$ & - \\
\hline \multirow[t]{2}{*}{ P.vulgaris $(n=1)$} & S & $1(100)$ & $1(100)$ & - & $1(100)$ & $1(100)$ & $1(100)$ & $1(100)$ & $1(100)$ & $1(100)$ & $1(100)$ & $1(100)$ & $1(100)$ \\
\hline & $\mathrm{R}$ & - & - & $1(100)$ & - & - & - & - & - & - & - & - & - \\
\hline \multirow[t]{3}{*}{ Citrobacter spps. $(n=6)$} & $S$ & - & $3(50)$ & $1(16.7)$ & $1(16.7)$ & $1(16.7)$ & $5(83.3)$ & $6(100)$ & $1(16.7)$ & $2(33.33)$ & $1(16.7)$ & - & $3(50)$ \\
\hline & I & - & $2(33.3)$ & - & - & - & $1(16.7)$ & - & - & $2(33.33)$ & $1(16.7)$ & $1(16.7)$ & - \\
\hline & $\mathrm{R}$ & $6(100)$ & $1(16.7)$ & $5(83.3)$ & $5(83.3)$ & $5(83.3)$ & - & - & $5(83.3)$ & $2(33.33)$ & $4(66.7)$ & $5(83.3)$ & $3(50)$ \\
\hline \multirow[t]{3}{*}{ Providencia spps. $(n=1)$} & S & - & $1(100)$ & - & $1(100)$ & $1(100)$ & $1(100)$ & $1(100)$ & - & $1(100)$ & $1(100)$ & - & $1(100)$ \\
\hline & I & - & - & $1(100)$ & - & - & - & - & - & - & - & - & - \\
\hline & R & $1(100)$ & - & - & - & - & - & - & $1(100)$ & - & - & $1(100)$ & - \\
\hline \multirow{2}{*}{$\begin{array}{l}\text { Acinetobacter spps. } n= \\
1\end{array}$} & $S$ & - & - & - & $1(100)$ & $1(100)$ & $1(100)$ & $1(100)$ & $1(100)$ & - & $1(100)$ & - & - \\
\hline & $\mathrm{R}$ & $1(100)$ & $1(100)$ & $1(100)$ & - & - & - & - & - & $1(100)$ & - & $1(100)$ & - \\
\hline \multirow[t]{3}{*}{ Total $n=44$} & $S$ & - & $20(45.5)$ & $5(11.4)$ & $33(75)$ & $33(75)$ & $34(77.3)$ & 43(97.73) & 18(40.9) & $30(68.18)$ & $33(75)$ & 8(18.18) & $31(70.5)$ \\
\hline & I & - & $11(25)$ & $9(20.46)$ & $3(6.8)$ & $1(2.3)$ & $3(6.8)$ & - & $4(9.1)$ & $5(11.37)$ & $2(4.5)$ & $7(15.9)$ & $3(6.8)$ \\
\hline & $\mathrm{R}$ & $44(100)$ & 13(29.6) & $30(68.2)$ & $8(18.2)$ & $10(22.7)$ & $7(15.9)$ & $1(2.27)$ & $22(50)$ & $9(20.5)$ & $9(20.5)$ & 29(65.91) & $10(22.5)$ \\
\hline
\end{tabular}

Note: Sen. Sensitivity, AMP Ampicillin, GEN Gentamycin, AMC Augmentin, CXT Cefoxitin, CTX Cefotaxime, CIP Ciprofloxacin, MER Meropenem, COT Cotrimoxazole, CAZ Ceftazidime, CHL Chloramphenicol, TET Tetracycline, NIT Nitrofurantoin, $S$ Sensitive, I Intermediate, $R$ Resistant

Table 3 Drug resistant patterns of Gram-positive bacterial isolates from urine samples of children at the FHCSH, Northwest Ethiopia, February--April, 2019

\begin{tabular}{llllllllll}
\hline Bacterial isolate & Sensitivity & ERY & CXT & CPR & TET & CHL & COT & GEN & NIT \\
\hline S.aurues, $n=3$ & S & $1(33.33)$ & $2(66.7)$ & $2(66.7)$ & $1(33.33)$ & $2(66.7)$ & $2(66.7)$ & $2(66.7)$ & $3(100)$ \\
& I & $1(33.33)$ & - & - & - & $1(33.33)$ & - & - \\
S.saprophyticus, $n=3$ & $\mathrm{R}$ & $1(33.33)$ & $1(33.33)$ & $1(33.33$ & $2(66.7)$ & - & $1(33.33)$ & $1(33.33)$ & - \\
& $\mathrm{S}$ & $2(66.7)$ & $2(66.7)$ & $2(66.7)$ & - & $2(66.7)$ & $2(66.7)$ & $2(66.7)$ & $3(100)$ \\
& $\mathrm{I}$ & $1(33.33)$ & - & $1(33.33)$ & $2(66.7)$ & $1(33.33)$ & - & - & - \\
Total, $n=6 / 50$ & $\mathrm{R}$ & - & $1(33.33)$ & - & $1(33.33)$ & - & $1(33.33)$ & $1(33.33)$ & - \\
& $\mathrm{S}$ & $3(50)$ & $4(66.67)$ & $4(66.67)$ & $1(16.67)$ & $4(66.67)$ & $4(66.67)$ & $4(66.67)$ & $6(100)$ \\
& $\mathrm{I}$ & $2(33.33)$ & - & - & $2(33.33)$ & $2(33.33)$ & - & - & - \\
& $\mathrm{R}$ & $1(16.67)$ & $2(33.33)$ & $1(16.67)$ & $3(50)$ & - & $2(33.33)$ & $2(33.33)$ & - \\
\hline
\end{tabular}


to cefoxitin, cefotaxime, ceftazidime, ciprofloxacin, meropenem, chloramphenicol, and nitrofurantoin. $K$. pneumoniae was another bacterial isolate that showed a high level of susceptibility to meropenem 5/5(100\%), ceftazidime, and nitrofurantoin 4/5(80\%) each (Table 2).

\section{Multidrug resistance patterns of bacterial isolates}

The overall multidrug resistance rate of the isolates was assessed and about 66\% (95\% CI 52-78, $N=33$ ) showed multidrug resistance. A higher rate of MDR was observed in Gram-negative bacterial isolates compared to Gram-positives. The majority of the Gram-negative isolates 31/44 (70.5\%) showed multidrug resistance (MDR). Particularly, the highest MDR was observed in Klebsiella specie, 6/7 (85.7\%) followed by Citrobacter species, 5/6 (83.3\%), and E. coli species, 18/44 (64.3\%) (Table 4).

\section{Extended spectrum beta-lactamase production}

In the beginning, a total of seven Gram-negative bacterial isolates (six E. coli and one K. pneumoniae) were candidates for ESBL production test. 6 bacterial isolates
(5 E. coli and $1 K$. pneumoniae) were phenotypically confirmed for the production of ESBL by using the double disk diffusion method; ceftazidime [30 $\mu \mathrm{g}]$ and ceftazidime-clavulanic acid [30/10 $\mu \mathrm{g}]$. A difference of $\geq 5 \mathrm{~mm}$ between zone diameters of ceftazidime and ceftazidime-clavulanic acid disk is taken to be phenotypic confirmation of ESBL production with fulfilling the criteria of CLSI-2018 [23].

\section{Antimicrobial susceptibility patterns of gram-positive bacterial isolates}

All Gram-positive isolates were 6/6(100\%) sensitive to nitrofurantoin followed by cotrimoxazole, cefoxitin, ciprofloxacin, chloramphenicol, and gentamycin, 2/3(66.7\%) each. About 1/3(33.33\%) of S. aureus showed MDR.

\section{Associated risk factors}

Based on the multivariate logistic regression model, two factors, such as the circumcision status of males (AOR = 18.99, 95\% C.I. $=5.5-65.353)$ and history of UTI $(\mathrm{AOR}=$ 6.42, $95 \% \mathrm{CI}=1.86-22.152$ ) were found to be the independent risk factors for UTI in children. Therefore,

Table 4 Multi-drug resistant profile of Gram-negative bacteria isolated from urine of UTI suspected children attending the FHCSH, Northwest, Ethiopia, February-April, 2019

\begin{tabular}{|c|c|c|c|c|c|c|}
\hline \multirow[t]{2}{*}{ Antimicrobial resistance pattern } & \multicolumn{5}{|c|}{ Bacterial isolate } & \multirow[t]{2}{*}{ Tota } \\
\hline & E. col & Klebsiella sp & Citrobacte & Acinetobacter & Providencia & \\
\hline AMP, TET, NIT & 1 & & & & & 1 \\
\hline AMP, COT, TET & 2 & & & & 1 & 3 \\
\hline AMP, GEN, TET & 1 & 1 & & & & 2 \\
\hline AMP, GEN, AMC & 1 & & & & & 1 \\
\hline AMP, AMC, COT & 2 & & & & & 2 \\
\hline AMP, GEN, AMC, TET & & 1 & & 1 & & 2 \\
\hline AMP, AMC, CIP, TET & 1 & & & & & 1 \\
\hline AMP, CIP, COT, CHL & 1 & & & & & 1 \\
\hline AMP, AMC, COT, TET & 1 & 1 & & & & 2 \\
\hline AMP, GEN, AMC, CTX, TET & 1 & & & & & 1 \\
\hline AMP, GEN, COT, TET, NIT & 1 & & & & & 1 \\
\hline AMP, AMC, COT, CHL, TET & & 2 & & & & 2 \\
\hline AMP, GEN, AMC, CHL, NIT & 1 & & & & & 1 \\
\hline AMP, AMC, CTX, CIP, COT, TET & 1 & & & & & 1 \\
\hline AMP, GEN, AMC, CXT, CTX, COT, CAZ & & & 1 & & & 1 \\
\hline AMP, GEN, AMC, COT, CAZ, CHL, TET & 1 & & & & & 1 \\
\hline AMP, AMC, CXT, CTX, COT, CHL, TET, NIT & & & 3 & & & 3 \\
\hline AMP, AMC, CXT, CTX, COT, CAZ, CHL, TET & & & 1 & & & 1 \\
\hline AMP, AMC, CXT, CIP, COT, CAZ, TET, NIT & 1 & & & & & 1 \\
\hline AMP, GEN, AMC, CTX, CIP, COT, CAZ, TET & & 1 & & & & 1 \\
\hline AMP, GEN, AMC, CXT, CTX, CIP, COT, CAZ, CHL, TET & 1 & & & & & 1 \\
\hline AMP, GEN, AMC, CXT, CTX, CIP, MER, COT, CAZ, CHL, TET & 1 & & & & & 1 \\
\hline Total & 18 & 6 & 5 & 1 & 1 & 31 \\
\hline
\end{tabular}


being previously infected with UTI had more than six times the likelihood of developing UTIs compared to those who had not infection. On the other hand, males who were not circumcised were 19 times higher to be culture positive than circumcised boys (Table 5).

\section{Discussion}

The prevalence of UTI in the present study was $16.7 \%$ (95\% CI 12.7-20.4, $N=50$ ). It is in line with the study done in Addis Ababa 15.8\% [18]. However, it is lower than the findings of the studies in Gondar, 26.45\% [19], and Hawassa, 27.5\% [8]. This difference might be a female predominance to Gondar University Hospital, $60.94 \%$ in contrast to our study $44.8 \%$. The majority of male study participants, $71.7 \%$ in the Hawassa University Hospital were not circumcised. Therefore, a tight foreskin may interfere with the normal passage of urine and can prevent the full emptying of the bladder $[25,26]$.

Though UTI can be caused by both Gram-negative and Gram-positive bacteria, Gram-negative bacteria are the most common cause of the infection, because the agents are the normal constituent of the normal intestinal microbiota [27]. Acquisition of UTI starts with periurethral contamination by uropathogens inhabiting in the gut, followed by colonization of the urethra and successive migration of the pathogen to the bladder [28]. Among these, E. coli is the predominant one [14, 29, 30]. Similarly, the present study reveals that $88 \%(44 / 50$, 95\% CI $80-96 \%$ ) of the isolate are Gram-negative bacteria. Of these, E. coli accounted for about $63.63 \%$ of Gram-negatives followed by Klebsiella species (15.9\%), and Citrobacter species (13.63\%). This predominance might be due to their unique structures such as flagella and pili, which help for their attachment to the uroepithelium and increases risks for infection [31]. Similar percentage of Citrobacter species, E. coli species, and Klebsiella species was documented in Nigeria, 10.7\% [32], in Iran, 57.4\% [33], and in Scotland, 19\% [3] respectively. A study in Bangladesh reported the same prevalence of $E$. coli, $63.3 \%$ of the total Gram-negative

Table 5 Predictors of urinary tract infections among children who attend pediatric OPD of FHCSH, Northwest Ethiopia, February to April, 2019

\begin{tabular}{|c|c|c|c|c|c|c|c|}
\hline Variables & & UTI N (\%) & No. UTI (\%) & $P$-value & COR & $P$-value & AOR \\
\hline \multirow[t]{3}{*}{ Age } & $<1$ & $11(3.7)$ & $25(8.4)$ & 0.043 & 0.372 (0.143_0.962) & 0.237 & $0.408\left(0.092 \_1.804\right)$ \\
\hline & 1_5 & $10(3.3)$ & $95(31.8)$ & 0.067 & 2.117 (0.949_4.723) & 0.111 & $3.12\left(0.766 \_13.36\right)$ \\
\hline & 6_15 & $29(9.7)$ & $129(43.1)$ & & 1 & & 1 \\
\hline \multirow[t]{2}{*}{ Sex } & Female & $30(10)$ & $145(48.5)$ & 0.022 & 2.07 (1.11_3.86) & & \\
\hline & Male & $20(6.7)$ & $122(73.9)$ & & 1 & & \\
\hline \multirow[t]{2}{*}{ Circumcision in boys } & No & $15(9.1)$ & $23(13.9)$ & 0.00 & 15.93 (5.27_48.09) & 0.00 & $18.99\left(5.5 \_65.35\right)$ * \\
\hline & Yes & $5(3.0)$ & $104(34.8)$ & & 1 & & 1 \\
\hline \multirow[t]{2}{*}{ Residence } & Rural & $10(3.3)$ & $81(27.1)$ & 0.08 & $1.98\left(0.92 \_4.28\right)$ & & \\
\hline & Urban & $40(13.4)$ & $168(56.2)$ & & 1 & & \\
\hline \multirow[t]{2}{*}{ Diabetes mellitus } & Yes & $13(4.3)$ & $16(5.4)$ & 0.00 & 0.195 (0.09_0.44) & & \\
\hline & No & $37(12.4)$ & $233(77.9)$ & & 1 & & \\
\hline \multirow[t]{2}{*}{ History of UTI } & Yes & $31(10.4)$ & $19(6.4)$ & 0.00 & 0.09 (0.05_0.18) & 0.003 & $6.42\left(1.86 \_22.15\right)$ * \\
\hline & No & $32(10.7)$ & $217(72.6)$ & & 1 & & 1 \\
\hline \multirow[t]{2}{*}{ History of catheterization } & Yes & $31(10.4)$ & $19(6.4)$ & 0.00 & 0.06 (0.03_0.13) & & \\
\hline & No & $23(7.7)$ & $226(75.6)$ & & 1 & & \\
\hline \multirow[t]{4}{*}{ Education of father } & Illiterate & $19(3.0)$ & $74(24.7)$ & 0.14 & $2.01\left(0.79 \_5.14\right)$ & & \\
\hline & primary & $17(5.7)$ & $74(24.7)$ & 0.88 & $1.07\left(0.47 \_2.43\right)$ & & \\
\hline & High school & $12(4.0)$ & $52(17.4)$ & 0.89 & $1.07\left(0.47 \_2.58\right)$ & & \\
\hline & College and above & $12(4.0)$ & $49(16.4)$ & & 1 & & \\
\hline \multirow[t]{4}{*}{ Education of mother } & Illiterate & $18(6.0)$ & $109(36.5)$ & 0.48 & $0.69\left(0.24 \_1.97\right)$ & & \\
\hline & Primary & $11(3.7)$ & $54(18.1)$ & 0.311 & $0.56\left(0.18 \_1.73\right)$ & & \\
\hline & High shcool & $16(5.4)$ & $42(14.0)$ & 0.03 & $0.30\left(0.10 \_0.0 .89\right)$ & & \\
\hline & College and above & $5(1.7)$ & $44(14.7)$ & & 1 & & \\
\hline \multirow[t]{2}{*}{ Malnutrition } & Yes & 18(6) & $32(10.7)$ & 0.00 & 3.81(1.92_7.58) & & \\
\hline & No & $32(10.7)$ & $217(72.6)$ & & 1 & & \\
\hline
\end{tabular}


bacterial isolates [34]. About 30/50 (60\%) of the isolate and 20/28 (72\%) of E. coli and Klebsiella species were isolated from females. This might be due to poor hygienic conditions, the proximity of anal and urethral openings, and relatively wide urethra [14].

All Gram-negative bacterial isolates 44/44(100\%) were resistant to ampicillin followed by augmentin 39/ 44(88.6\%) and tetracycline 36/44 (81.8\%). Similar findings were seen in Scotland, 93\% [35] and in Pakistan, $100 \%$ [36]. The reason may be due to the continuous use of these drugs for many years, easily availability, selfprescription, the tendency of patients using relatively cheaper antibiotics for all types of infection, and misuse. About 43/44(97.3\%) of isolates were sensitive to Meropenem. This might be due to the unavailability of this drug in the area. As Table 2 shows, ciprofloxacin, cefoxitin, and ceftazidime showed the best performance against $E$. coli. This finding was almost similar with the findings reported at Gondar Hospital and Yekatit 12 hospital [18]. According to the findings in Gondar Hospital, the sensitivity of gentamicin and cotrimoxazole to E. coli was 80 and 73\% [19] respectively. However, in the present study, the susceptibility to the above-listed drugs were $15 / 28(53.4 \%)$ and $16 / 28(57.1 \%)$ respectively. This might be due to the gradual increase of drug resistance/ selective pressure of bacteria to the drug/mutation, or the difference in antibiotic practices in the study area. Similar research from Iraq also revealed $75 \%$ sensitivity to chloramphenicol [2].

All Gram-positive isolates showed 6/6(100\%) sensitivity to nitrofurantoin. A similar result was reported at Yekatit 12 hospital 100\% [18].The reason for the effectiveness of this drug might be, due to the nature of having multiple mechanisms and site of actions of the drug with a non-specific blockage of protein synthesis limited access to the drug, and narrow-spectrum nature of the drug. However, about $71.4 \%$ resistance rate was documented in Hawasa [8]. Higher resistance to this antibiotic is perhaps due to its wrongly usage as an empirical therapy.

Furthermore, the overall MDR prevalence in this study was (66\%) (95\% CI 52-78, N=33). Specifically, Gramnegative bacterial isolates showed significant level of MDR 31/44(70.5\%) compared to Gram-positive bacteria $2 / 6(33.33 \%)$. This was comparable to the findings reported in Gondar 58.53\% [30] and Addis Ababa, 73.7\% [18]. Although antimicrobial resistance comes primarily as a result of selective pressure on susceptible microbes by the use of therapeutic agents, there are also further multiple factors for the spread of resistance. Using broad-spectrum agents, easy availability of antimicrobials in non-controlled pharmacy, sub-standard/poor drug quality, treatment termination, and over-prescription due to a poor diagnostic set-up or fear of loss of follow- up are among common factors enhancing antimicrobial resistance [37].

The emergence of resistant strains among uropathogens are alarmingly increasing with different resistance patterns [38]. Acquisition of resistance might be either mutational (changing the target site of a bacteria within its genetic material) or acquisition of new genetic material from other bacteria. This problem is also magnified by an irrational use and poor administration of drugs. Once a patient acquires resistant strain bacteria, then it transfers antibiotic resistance genes to other bacteria [39].

The present study also demonstrated the prevalence of ESBL producing strains which was $13.6 \%$ (95\% CI $6.5-32.3 \%, N=6)$. The prevalence is dynamically rising just due to multiple factors; lack of early treatment of the case, fast transmission ESBL strains to the community and healthcare institutions, and environmental stress. Inappropriate use of carbapenems, increased use of third-generation cephalosporin and quinolones in the community, stool-mediated infections, and the existence of the ESBL gene in the plasmid are other possible factors [40]. Having plasmids and other mobile genetic materials can help ESBL producing bacterial strains to be resistant for other multiple antimicrobial agents. This may let physicians to have narrow treatment options and increase the mortality and morbidity of patients infected with ESBL producing bacteria [41].

In this study, associated factors were also determined. Among assessed factors, the history of previous UTI and male uncircumcision was the independent risk factors for the acquisition of UTI. A recurrent urinary tract infections can be attributed to two common enhancing factors: ascending of identical urethral microbiota, particularly uropathogenic $E$. coli to the bladder and/or untreated chronic/persistent bladder infection resulted from either ascending or bloodstream infections [42]. This fact is supported by a study done in Denmark, and it depicted that $77 \%$ of recurrent UTIs have resulted from infection with identical uropathogenic E. coli strains [43]. Adhesion structures like $\mathrm{P}$ and type 1 pili may help E. coli for progression to the bladder [44].

Having facultative intracellular multiplication in uroepithelial cells helps E. coli to escape from being killed by humoral immunity and antimicrobial agents. This multiplication takes place to a certain extent and forms loose colonies and escapes out to the lumen of the bladder. However, some of the bacterial colonies remain intracellularly and can be a reservoir for persistent infection [45]. This study, however, couldn't assess the molecular characteristics of bacterial isolates. 


\section{Conclusion}

The prevalence of UTI in children was high, and considerably a high proportion of MDR strains were observed in the present study. Previous history of UTI and male uncircumcision were the predictor variables of UTI.

\section{Abbreviations}

AOR: Adjusted Odds Ratio; ATCC: American Type Culture Collection; Cl: Confidence Interval; CLED: Cysteine-Lactose-Electrolyte Deficient Agar; CLSI: Clinical Laboratory Standards Institute; CSA: Central statistical agency of Ethiopia; ESBL: Extended Spectrum Beta Lactamase; FHCSH: Felege-Hiwot Comprehensive Specialized Hospital; MDR: Multi-Drug Resistance; MHA: Muller-Hinton Agar; MSU: Mid-Stream Urine; UTI: Urinary Tract Infection

\section{Acknowledgments}

The authors would like to thank all the study participants and parents for their good collaboration. The authors would like also to thank the University of Gondar, Amhara Regional Health Bureau, Ethiopian Public Health Institute, and Felege-Hiwot Microbiology laboratory for logistic and material supports.

\section{Authors' contributions}

AF did conceptualization, analyzing the data, methodology designing, investigation during laboratory work, writing original draft and review the final manuscript. MD did conceptualization, methodology designing, writing original draft and review the final manuscript. SE did conceptualization, analyzing the data, methodology designing, writing original draft and review the final manuscript. TB did conceptualization, methodology designing, investigation during the laboratory work, writing original draft and review the final manuscript. All authors have read and approved the manuscript.

\section{Funding}

This study was not funded.

\section{Availability of data and materials}

The datasets used and/or analyzed during the current study are available from the corresponding author on reasonable request.

\section{Ethics approval and consent to participate}

An ethical clearance letter was obtained from the Departmental Research and Ethics Review Committee of the school of biomedical laboratory science. The reference number of the ethical letter was "Ref no- SBMLS/ 2123/11". Written consent was obtained from participants and informed as their participation was voluntary. Study participants were also informed about the purpose of the study. Confidentiality was maintained at all levels of the study. In addition, study participants' involvement was based on a voluntary basis and participants who were unwilling to take part in the study and those who need to quit their participation at any stage were informed to do so without any restriction. Consent to participate was obtained from the parents/guardians of study participants under the age of 16 .

\section{Consent for publication}

Not applicable.

\section{Competing interests}

The authors declare that they have no competing interest.

\section{Author details}

${ }^{1}$ Wogera primary hospital, North Gondar, Gondar, Ethiopia. ${ }^{2}$ College of Medicine and Health Sciences, School of Biomedical and Laboratory Sciences, Department of Medical Microbiology, University of Gondar, Gondar, Ethiopia.

Received: 15 July 2019 Accepted: 8 September 2020

Published online: 16 September 2020

\section{References}

1. Bilman FB, Karadeniz N. YetikM. Profile of children's urinary tract infection, evaluation of risk factors and review of the literature. Pediatr Clin N Am. 2006;53(3):379-400.
2. Ali MR. Detection of uropathogens in urinary tract infection and their sensitivity to many antimicrobial agents. Ibn AL-Haitham J Pure Appl Sci. 2017;26(3):15-24.

3. Wolff $\mathrm{O}$, Maclennan C. What is the appropriate empiric antibiotic therapy in uncomplicated urinary tract infections in children in developing countries? Int Child Health Rev Collab. 2007:53(3):11-31.

4. Zorc JJ, Kiddoo DA, Shaw KN. Diagnosis and management of pediatric. Clin Microbiol Rev. 2005;18(2):417-22.

5. Arshad M, Seed PC. Urinary tract infections in the infant. Clin Perinatol. 2015; 42(1):17-28.

6. Foxman B, Brown P. Epidemiology of urinary tract infections: transmission and risk factors, incidence, and costs. Infect Dis Clin N Am 2003:17(2):227-41.

7. Gachuhi GT. Antibiotic susceptibility pattern of bacterial uropathogens isolated from patients in Nakuru level 5 hospital, Kenya. Kenyatta University; 2017.

8. Mitiku E, Amsalu A, Tadesse BT. Pediatric urinary tract infection as a cause of outpatient clinic visits in southern Ethiopia: a cross sectional study. Ethiop J Health Sci. 2018:28(2):187-96.

9. Smelov $\mathrm{V}$, Naber $\mathrm{K}$, Johansen TEB. Improved classification of urinary tract infection: future considerations. Eur Urol Suppl. 2016;15(4):71-80.

10. Luna-Pineda VM, Ochoa SA, Cruz-Córdova A, Cázares-Domínguez V, Reyes Grajeda JP, Flores-Oropeza MA, et al. Features of urinary Escherichia coli isolated from children with complicated and uncomplicated urinary tract infections in Mexico. PLoS One. 2018;13(10):e0204934.

11. Masika WG, O'Meara WP, Holland TL, Armstrong J. Contribution of urinary tract infection to the burden of febrile illnesses in young children in rural Kenya. PLoS One. 2017;12(3):e0174199.

12. Aryal B, Mandal PK, Tripathi PD. Microbiological spectrum and susceptibility pattern of clinical isolates from children suspected of urinary tract infection, visiting Kanti children hospital, Kathmandu. Glob J Med Res. 2014;14(7):1-5.

13. Maharjan G, Khadka P, Siddhi Shilpakar G, Chapagain G, Dhungana GR. Catheter associated urinary tract infection and obstinate biofilm producers. Can J Infect Dis Med Microbiol. 2018;1(1):1-7.

14. Sargiary P, Baro L, Choudhry G, Saikia L. Bacteriological profile and antimicrobial susceptibility pattern of community acquired urinary tract infection in children: a tertiary care experience. J Dental Med Sci. 2016; 15(6):61-5.

15. Dramowski A, Whitelaw A, Cotton M. Burden, spectrum, and impact of healthcare-associated infection at a south African children's hospital. J Hosp Infect. 2016;94(4):364-72

16. Aiyegoro O, Igbinosa O, Ogunmwonyi I, Odjadjare E, Igbinosa O, Okoh A. Incidence of urinary tract infections (UTI) among children and adolescents in Ile-Ife, Nigeria. Afr J Microbiol Res. 2007;1 (f2):13-9.

17. Fredrick F, Francis JM, Fataki M, Maselle SY. Aetiology, antimicrobial susceptibility and predictors of urinary tract infection among febrile underfives at Muhimbili National Hospital, Dar Es Salaam-Tanzania. Afr J Microbiol Res. 2013;7(12):1866. https://doi.org/10.5897/AJMR.

18. MergaDuffa Y, TerfaKitila K, MamuyeGebretsadik D, Bitew A. Prevalence and antimicrobial susceptibility of bacterial Uropathogens isolated from pediatric patients at Yekatit 12 hospital medical college, Addis Ababa, Ethiopia. Int J Microbiol. 2018;1:1-7.

19. Ayelign B, Abebe B, Shibeshi A, Meshesha S, Shibabaw T, Addis Z, et al. Bacterial isolates and their antimicrobial susceptibility patterns among pediatric patients with urinary tract infections. Turkish J Urol. 2018:44(1):62.

20. Derbie A, Amdu A, Alamneh A, Tadege A, Solomon A, Elfu B, et al. Clinical profile of tetanus patients attended at FelegeHiwot referral hospital, Northwest Ethiopia: a retrospective cross-sectional study. Springer Plus. 2016:5(1):892

21. Mcgoldrick M. Urine specimen collection and transport. Home Healthc Now. 2015;33(5):284-5.

22. Nelson CP, Hoberman A, Shaikh N, Keren R, Mathews $R$, Greenfield SP, et al. Antimicrobial resistance and urinary tract infection recurrence. Pediatrics. 2016:137(4):e20152490

23. Weinstein MP, Limbago B, Patel J, Mathers A, Campeau S, Mazzulli T, et al. M100 performance standards for antimicrobial susceptibility testing. In.: CLSI; 2018.

24. Magiorakos AP, Srinivasan A, Carey R, Carmeli Y, Falagas M, Giske C, et al. Multidrug-resistant, extensively drug-resistant and pandrug-resistant bacteria: an international expert proposal for interim standard definitions for acquired resistance. Clin Microbiol Infect. 2012;18(3):268-81. 
25. Irkilata L, Aydin HR, Aydin M, Gorgun S, Demirel HC, Adanur S, et al. Preputial bacterial colonization in uncircumcised male children: is it related to phimosis? J Pak Med Assoc. 2016;66(3):312-5.

26. Kanematsu A. Management of phimosis as a risk factor of urinary tract infection: an Asian perspective. Urol Sci. 2016;27(4):190-2.

27. Todar K. The normal bacterial flora of humans. 1st ed. Madison: University of Wisconsin; 2008

28. Flores-Mireles AL, Walker JN, Caparon M, Hultgren SJ. Urinary tract infections: epidemiology, mechanisms of infection and treatment options. Nat Rev Microbiol. 2015;13(5):269.

29. Mirsoleymani SR, Salimi M, ShareghiBrojeni M, Ranjbar M, Mehtarpoor M. Bacterial pathogens and antimicrobial resistance patterns in pediatric urinary tract infections: a four-year surveillance study (2009-2012). Int J Pediatr. 2014;1:1. https://doi.org/10.1155/2014/126142.

30. Ikram R, Rebecca Psutka R, Carter A, Priest P. An outbreak of multi-drug resistantEscherichia coli urinary tract infection in an elderly population: a case-control study of risk factors. BMC Infect Dis. 2015;15:224

31. Bublitz DC, Wright PC, Bodager JR, Rasambainarivo FT, Bliska JB, Gillespie TR. Epidemiology of pathogenic enterobacteria in humans, livestock, and peridomestic rodents in rural Madagascar. PLoS One. 2014;9(7):e101456.

32. Garba GIBI, Aminu MS, Onazi SO, Yusuf I, Adelakun MB, Kolawole T. Childhood urinary tract pathogens and antibiotic susceptibility seen at Gusau, Nigeria. Trop J Nephrol. 2017;10(1):7-12.

33. Mashouf RY, Babalhavaeji H, Yousef J. Urinary tract infections: bacteriology and antibiotic resistance patterns. Indian Pediatr. 2009;46:7.

34. Nazme NI, Al Amin A, Jalil F, Sultana J, Fatema NN. Bacteriological profile of urinary tract infection in children of a tertiary care hospital. Bangladesh $J$ Child Health. 2017:41(2):77-83.

35. Michael CA, Dominey-Howes D, Labbate M. The antimicrobial resistance crisis: causes, consequences, and management. Front Public Health. 2014;2:145.

36. Hassan SA, Jamal SA, Kamal M. Occurrence of multidrug resistant and ESBL producing E. coli causing urinary tract infections. Aust J Basic Appl Sci. 2011;1:1.

37. Burroughs T, Najafi M, Lemon SM, Knobler SL. The resistance phenomenon in microbes and infectious disease vectors: implications for human health and strategies for containment: workshop summary. Washington (DC): National Academies Press; 2003.

38. Devrim F, Serdaroğlu E, Çağlar I, Oruç Y, Demiray N, Bayram N, et al. The emerging resistance in nosocomial urinary tract infections: from the pediatrics perspective. Mediterr J Hematol Infect Dis. 2018;10:1.

39. Gniadkowski M. Evolution and epidemiology of extended-spectrum $\beta$ lactamases (ESBLs) and ESBL-producing microorganisms. Clin Microbiol Infect. 2001;7(11):597-608.

40. Ikeda Y, Mamiya T, Nishiyama H, Koseki T, Mouri A, Nabeshima T. Risk factors for extended-spectrum $\beta$-lactamase-producing Escherichia coli infection in hospitalized patients. Nagoya J Med Sci. 2012;74(1-2):105.

41. Fennell J, Vellinga A, Hanahoe B, Morris D, Boyle F, Higgins F, et al. Increasing prevalence of ESBL production among Irish clinical Enterobacteriaceae from 2004 to 2008: an observational study. BMC Infect Dis. 2012;12(1):116

42. Hanna-Wakim RH, Ghanem ST, El Helou MW, Khafaja SA, Shaker RA, Hassan SA, et al. Epidemiology and characteristics of urinary tract infections in children and adolescents. Front Cell Infect Microbiol. 2015;5:45.

43. Ejrnæs K. Bacterial characteristics of importance for recurrent urinary tract infections caused by Escherichia coli. Dan Med Bull. 2011;58:B4187.

44. Melican K, Sandoval RM, Kader A, Josefsson L, Tanner GA, Molitoris BA, et al. UropathogenicEscherichia coli $P$ and type 1 fimbriae act in synergy in a living host to facilitate renal colonization leading to nephron obstruction. PLoS Pathog. 2011;7(2):e1001298.

45. Mysorekar IU, Hultgren SJ. Mechanisms of uropathogenicEscherichia coli persistence and eradication from the urinary tract. Proc Natl Acad Sci. 2006; 103(38):14170-5.

\section{Publisher's Note}

Springer Nature remains neutral with regard to jurisdictional claims in published maps and institutional affiliations.

Ready to submit your research? Choose BMC and benefit from:

- fast, convenient online submission

- thorough peer review by experienced researchers in your field

- rapid publication on acceptance

- support for research data, including large and complex data types

- gold Open Access which fosters wider collaboration and increased citations

- maximum visibility for your research: over $100 \mathrm{M}$ website views per year

At BMC, research is always in progress.

Learn more biomedcentral.com/submissions 